\title{
Paulo Freire's Work and the Dialogue with the Interculturality
}

\author{
Cybele de Faria e Soares, Cesar Guerra Scarpelli, Elisa Martins Luckner \\ University of São Paulo, Brazil
}

\begin{abstract}
The present paper leads us to think about Adults Education, approaching the discussion to Paulo Freire's work, as an important Brazilian researcher on the selected are. From this point of view, it is noticed the difference between children literacy and Adults literacy, which regards a consideration about the early experience lived by those students. In addition, the classroom studies with adults have multiple cultures lived and experienced in ways of thinking and acting. In São Paulo, Brazil, some of the classrooms for Adults education consist of migrants who came from the poorest regions of the country and moved to this dynamic center of the country in the hope of better life for themselves and their families. In this respect it is important to consider the meaning of multiculturalism and migration to these people. Therefore, thinking about an intercultural dialogue and their palavramundo can only favor the pedagogical practice. This way, the education is treated as a political act in despite of a banking pedagogy, which intends to promote autonomy but, in matter of fact, critic citizens with independence to think about their own places inside the society, or even to promote changes, defending their thoughts and political positions. Another important point for analysis is the diversity of adults in the classroom and the potential that their palvramundo has in the classroom dynamic in order to contribute to the exchange between cultures and, in addition to respect them, consider them in the construction of knowledge, in interculturalism molds.
\end{abstract}

\section{Introduction}

Our research in Adults Education studies Paulo Freire's work in order to give a most important meaning to the students' performance, while involved in this teaching modality. To begin with we made ourselves the following questions: what does Professor Freire teach us about the adults school? What can the palavramundo (worldword) help us to account for the dynamics of multiculturalism in the classroom? Any discussion in this context cannot dispense an accurately reading and reflection about the thoughts instigated by the Brazilian educator Paulo Freire, who dedicated his life to academic work and his intellectual focus to this field of education. In intercultural dialogue with the palavramundo can facilitate and open the practice of teachers that may appropriate the palavramundo of students to be able to develop a dynamic that respects and gets this student as a participant in this society with its own history and culture. We find the concept palavramundo in his work "The importance of the act of reading" in which the teacher makes us reflect that one of the major difficulties of education is not to consider any prior knowledge, experiences and cultures that this student has, so do not understand what their needs are keeping us away from the reality of the school, forcing a shallow knowledge, merely depositary and homogeneous.

\section{Methodology}

Freire brings us the importance of an early experience on an interpretation process, to develop later the writing and reading exercises, not before it. He said that the reading act involves much more than a simple mechanical motion and a systematic reading of the written word. This process should not be a language reading without some kind of discussion, leading us to think about our reality. Both practices need to connect each other in a dynamically way, promoting a relation between text and context, as also a reflective and understandable reading.

This instigates a reflection about the importance on bringing the contents already constructed and experienced to improve the educational reality itself. However it is necessary to think: does this occur? Does the daily life inside classrooms, the students reality, youth and adults, their thoughts, their readings of the world, are considered relevant?

Paulo Freire developed into one of his major works - Pedagogy of the Oppressed [7], a critique 
of the knowledge and skills that are not developed and built through the history and the lack of relation between the reality of the participants on society, which in most cases are oppressed and excluded from the educational process as they already know many things without importance to the school nowadays. The whole educational process is imposed on them through policy decisions, what Freire calls as a "banking pedagogy", which is an educational process that develops through the simple "knowledge warehouse", or we could say the simply acceptation of this knowledge, while students only would develop an act of memorization. Freire also affirms that people, as receivers, would be seen as having their "empty heads", which should be completed by the knowledge already established and which are generally guided by the ideology of the dominant group. The criticism of this pedagogy also focuses on the idea that there is a "standard" education, a pattern that homogenizes all and excludes many social groups that are distant and so this pattern are stigmatized and classified as worse, or a lower "culture".

Instead of communicating, the educator makes" deposits and reports" that students, mere incidents, patiently receive, memorize and repeat. It beholds the banking concept of education, in which the only leeway given to the students is to receive those deposits, saving and archiving them. Margin to be collectors or archive makers of collected things [7].

Reflecting on education within the concept of Pedagogy of the Oppressed [7], we can realize what has proposed Paulo Freire with the idea on building an education with a freedom function. People would build their own story, being agents of their own knowledge and the act of educating would cease to be that mechanic motion hierarchically imposed from the top down and so, therefore, there will be a dialogue between their reality and the act of teaching, as well the act of learning, considering everything that someone can comprehend having touch with culture and living it. Thinking about that, there are so many spaces where the knowledge process for release may occur, expanding beyond the school environment to many discussions that with correlate with our daily life. Culture, in turn, is replaced by the mean value because it is not something imposed, pre-cast and drawn, but is each one's life expressing the relationship of teaching and learning, as well to teachers as learners and instructors, with living experiences and knowledge discarded by their work; as well to students suffering with new concepts disconnected to earlier knowledge. It means that education and the school will be a place in which many cultures and knowledge, not a single knowledge, can coexist with multiple values, minimizing, if not undermining, the hierarchy between it lately.

It is important to reflect about the impact of the ideas of Freire in Brazil, which until today has a high number of illiterates and semi - illiterates, and terrible results in levels of education (especially in the area of exact sciences). So designing an education whose role is not to shape the students to what befits society, but will be a new understanding on how the society with all its prior knowledge and culture, possibly the development of a fairer education that could help in raising the literacy rate of the Brazilian education (As Paulo Freire was able to do in certain regions of Brazil), as well in many other aspects that all the learning process through the first step on the literacy may be improved.

Our practical experience on Adults Educational area had shown us how these students bring with them a low self-steam because they are coming back to school out of the official age. Many testimonials of students as well of some of their teachers had should us the importance of new methodologies, to include them in a new culture, the school environment. Some of them are inside classes because they need to be graduate for better jobs positions, but as they carry many life experiences and want to be heard, most part of these groups respect teachers with an inferiority feeling, starting to believe that these previous knowledge doesn't mean anything to the school, to their works, to the society. When the educators encourage them to exercise their autonomy in an intellectual work, connecting their accounts to the subject in discussion, they can build a prominent and useful knowledge. Some of those testimonials clarified that those teachers had to change their ways of explain or discuss any subject considering the difference between Adults education classes and regular ones. This way, literacy and also the continuance of education in process may stand with meaningful formation, promoting changes and critical thoughts, individual but vast in all manners of facts.

Thinking about this education presented by Professor Paulo Freire, he realized that there is no neutrality in education because the whole instructional process is immersed in a thought oriented and political ideals, where someone will be "winning meat or not on the relationship between the acts to terminate or to announce " [4], which leads us to think: "to whom and why, so against 
whom and what we do educate and to whom and why, so who and what, develop political activity?" [4]. Again, the approach between education and politics is clear.

Within this general framework proposed by the Brazilian educator is possible to realize the necessity of an education that is useful, that is built with time, as stating in his book Pedagogy of Autonomy [6]:

So even, thinking with rightness puts the teacher or, more broadly, the school, the duty to not only respect the knowledge that students have, especially those from lower income groups of the community that come to it - with constructed knowledge in practice - but also as for over thirty years I have been suggesting, discuss with students the reason for some of this knowledge in relation to the teaching of content [6].

This statement expands the idea that just listening and respecting carefully can involve these learners in the educational process, so we will be including their history and culture inside our discussions, since much more is needed, we must reflect, allocate, discuss and understand even more, designing the same consideration of each one's life. "The crop circle at the Paulo Freire's method revive life in profound criticism [6]:

It is important to highlight how an understanding of the world expands into a liberating vision of education: Paulo Freire had adopted as its motto that "the world is not; the world is being " and that belief was worth for him too, because every minute was a unique opportunity, to act to change the world, and in it, people, standing, he also transformed himself. And the possibility of even believing deeply in some values , afford" reevaluating it" tomorrow from new historical - cultural conditions. This is why this teacher was always ahead of his time [1].

Therefore, the mean idea is to shatter with the previous point of view of a fixed world with a culture with all answers, alone, but changing it can be constructive, as discussed and reviewed in all areas of life. And we can consider the participation of all social groups with all cultures doing it, as they represent this new scenario, with their life experiences well expressed in and out of school.

A baseline point for Freire is critical to the imposition of a single cultural model. Involved in the act of teaching with a perceive turn, this contrast between his reality and what is transmitted, achieving most often identifying this surface about the content they bring. The lack of neutrality of education is evident in the educational activity. "The contradictions that characterize society are being penetrated in the intimacy of educational institutions, where systematic education is giving up while changes their role or their reproductive effort of the dominant ideology." [4].

Paulo Freire let us the following premise: "Education is a political act." [4] and therefore, the ways of organizing education are branded, in most cases, by oppressors political ideologies. Education is structured as an essential piece of the production gear for the labor market, but now we can notice an urgent necessity for appropriate subjects which should promote autonomy while they could understand their places in this system, learn how to develop an individual though, or even a political position to themselves, as active citizens within our society. But a possible "gateway" for understanding the social world of work in the foundations of the capitalist system is based in a cultural understanding. "The globalizing processes settle down interculturalism when creating modern world markets for material goods and money, messages and migrants" [3]. The teacher cannot do without this understanding cultural dynamics in the classroom and in the construction of knowledge with these adult learners.

In São Paulo, Brazil, some of the classrooms for Adults education consists full of migrants who came from the poorest regions of the country and moved to this dynamic center of the country in the hope of better life for themselves and their families. They have particular knowledge that doesn't dialogue with anything learned at school. In this respect it is important to consider the meaning of multiculturalism and migration to these people, because if it start to be considered inside the classroom the work to be done not only in literacy process, therefore, thinking about an intercultural dialogue and their palavramundo can only favor the pedagogical practice. Other important thing to be considered in this matter is the huge number of students that stopped to study in the formal age, got in touch with school again because of the necessity for better job position, that go away again, while does not understand the language used by the teachers, can't comprehend their explanations and, ashamed by not knowing, doesn't ask at all. Noting this, some teachers try to do get in touch with their social and historic lives, otherwise will not be able to teach. Their job include not only to prepare a class to teach, researching and them talking, but also starts to listen, to know what they know 
previously, to also know where it can link with school subjects and how, opening to ways on doing it, what promotes different projects, proposals and methodologies.

This way, the education is treated as a political act, in despite of a banking pedagogy, which intends to promote autonomy as possible, starting where the students are in the beggining but, in matter of fact, nowadays the practical always critic citizens with independence to think about their own places inside the society, or even to promote changes, defending their thoughts and political positions. Another important point for analysis is the diversity of adults in the classroom and the potential that their palvramundo has in the classroom dynamic in order to contribute to the exchange between cultures and, in addition to respect them, consider them in the construction of knowledge, in interculturalism molds.

Mayo [8], University of Malta, is also upholder of an education that considers all subjects, that is intercultural. In an article in Lusophone Journal of Education, he discuss Paulo Freire's studies with an emphasis on dialogue inter -ethnic. While exploring is possible to notice the difference between our reality from what he researched (he works with immigrants and us, with adults), but his work matters because reiterates the need to listen to the other testimonials of life, opening the world others to a better understanding about each other as a great possibility to discover ourselves while confronting what we know to what we are listening and learning.

With an enumerate list of challenges for educators who work with the various ethnic groups, among them, some topics serve us: we should not look at them as "deficits", we should be wary of representations of the constructs of "the other" while critical educators need to transform themselves into "border-crossers", must beginning with the understanding of something about the culture of others, including religion" [8]. It endorses the speech defense's ending the position of the cultural superiority of one group, over another, to get through an open dialogue.

When Paulo Freire and another educator, Moacir de Góes, began thinking about adults literacy they realized that this field was requiring an appropriate adequacy, leading with more specific considerations because it guards peculiarities in comparison to children literacy [9]. In other words, there was no adequacy of language, curriculum, methodologies, considering this group's specific needs. Therefore, Freire argues that we cannot allow youth and adults to be treated like children within the school. He justifies it explaining that adults have a life history that should be considered, they have a palavramundo already established, or so their own worldword.

The necessity of an education whose function releases people is urgent, where the text will have to know the context and its meaning. For this the Brazilian educator Paulo Freire brings us an important purpose and useful concept, the palavramundo, which represents all the previous knowledge that people carry with them in all their experiences, feelings and interpretations of the world. Understanding the palavramundo is valuable especially when it comes to learning processes (reading, writing, adults literacy, etc.), For "Reading the world precedes reading the word, so that posterior reading cannot dispense the continuity of that reading" [4]. There's no possible liberating education without reflecting on the importance of considering palavramundo, this prior knowledge on the act of educating, as it regards all the interpretation processes that leads any students while reading or comprehending culture, in any possible way it may be offered.

The discussion about the palavramundo initially appears in the book "The importance of the act of reading : Three items that complete a work" that aims to discuss the construction of the appropriation of knowledge especially in a reading approach that would be contrary to the Pedagogy of the Oppressed, whose proposal is to reflect the value of the specific knowledge of each person individuality on the construction of the act of teaching, also considering how different cultures (especially those related to people with lower qualities in life) should discuss and participate in the content taught.

To understand the palavramundo Freire performs a dive in its infancy noting that the development of knowledge was presented to him long before the moment when he would be taught at school. This educator's immersion recalls his life as a child in the northeastern state of Pernambuco, whose images and experiences that had already demonstrated its way of reading and understanding the world was determinate through living in that particular part of Brazil. "Text", "words" and "letters" not framed in educational systematization which would have imposed a different representation.

The " Text ", " words " and " letters " that are embodied in the context of singing birds - the Tanager, the pro - looks - way - that comes, the thrush $[\ldots]$ the rainwater kidding geography : making lakes, islands, rivers, streams [... ] the smell of flowers roses, jasmine - in the body of the tree, the 
bark of fruit in different color shades of the same fruit at different times [4].

This way, is possible to realize the importance of enlightening manner of observations, as the reading of this entire world, makes up the act of reading and learning in order to possibly the interpretation in itself. Compare, connect, watch and contextualize a part of all this construction. By observing the phases of the fruit there is a sequence of ideas and interpretations, when to know which fruits are ripe is to understand a number of factors, which together build the language that reading the words without context, without the world, are only words that doesn't build knowledge, just gives a mechanical perception of the language. It is necessary to understand what was our reading of the world and especially to us, which is the reading world around us, considering people and their cultures on it.

Freire says that all this "archeology" of his past and how he processed his act of reading was important to understand the process of adults literacy for it is" as a political act and an act of knowledge, therefore, as a creative act " [4]. The palavramundo makes our understanding about education, especially with adults as " empty heads "become too has no meaning at all, as it's necessary that this act of learning start now to be creative, to be meaningful, linked with the reality of the learner, that already have the knowledge on oral expressions, needing to learn how to transcribe and therefore, to read interpreting what does it means to him or her, thinking that all answers can be relevant. However, it is required for an interconnection where the words should actually have meaning, where this word is a "specific agent" which constitutes the adult's life (for example, a brick mason with the word brick and a housewife with the word flour, etc.).

An educational space that understands respects and experiences the palavramundo of their students provides a useful knowledge that has meaning for all people and cultures. "Learning to teach is not to transfer knowledge but to create opportunities for their own production or its creation."[4], meaning that this work makes the palavramundo alive. "When I walk into a classroom I must be open to the inquiries, the curiosities, questions from students" [4].

About palavramundo Elter Manoel Carlos says that the concept of palavramundo is presented in a pedagogical -political thought.
Paulo Freire. Marked by a turbulent historical period and existential pessimism (Latin America, Europe, Africa), where he dominated a vision of the school as a space of social reproduction of ideologies; Paulo Freire, with the strength of his existential optimism and faith in human nature introduced, in education, to contestation, utopian, mobilizing and hopeful language, directed to the future, giving rise to a pedagogy that transforms (inter) subjectively human consciousness" [2].

When we think about palavramundo, the field of action and perception of education expand in the act of teaching and learning. The school is not only one educator, but various institutions present in people's lives, inside their lives. Churches, NGOs and public libraries, for example, are spaces of knowledge that are immersed in that reality and, in general, in the individual history of people that attend, divulging, collecting, producing, reproducing and discussing culture in all kinds of speeches.

In the Importance of the act of reading in the second article is valued the function of public libraries, since that, according to Freire, these are spaces that can involve the whole community in the construction of knowledge. According to the educator, the libraries end up being only a "silent deposit of books" [4], and as proposed, it becomes alive and useful, suggesting that visitors can leave in your region, searching for a proper place for legends and stories of his acquaintances among other things on its basis, to build their own literature, through leaflets, texts or even videos, or we could say, by getting in touch with all disposed cultures.

The teacher develops a very important role in building an education as a liberating practice, as it should be positioned in a humble way in the construction of knowledge in all formal and nonformal educational spaces. Only with the construction of coherent dialogues where no student or teacher wants to put only one knowledge, culture or point of view as better than the other, an education for the purpose of liberation is possible.

A great job, a popular, especially peasant area that could be developed by librarians, documentalists educators, historians, would, for example, do the survey of the history of an area, through taped interviews that older and older residents of this area, presented as a witness, were setting the fundamental moments of their common history. Over time it would have a collection of stories 
that would make living part of the history of the area at bottom." [4].

We realized the necessity on building a new conception about reading and how it develops naturally transposing the limited physical space of the school and the rules imposed on it to be considered correct. Although, what would be a correct reading? For the educator Paulo Freire, would possibly not one interpretation, as required hierarchically by authoritarian oppressors, who just impose rules and paths that should be followed. In his study, the researcher Elter Manoel Carlos describes in the following:

Today, when we refer to the concept of reading we report us not only the powers that the subject has to master the techniques of graphical decryption, but essentially, the ability to interpret, analyze and understand the content of a given text. Initially, the term reading had a more limited meaning, since it was limited essentially to the domain of skills and competencies of identifying graphic symbols, rules of punctuation and its junction to produce sentences. Therefore, traditionally, the literate guy was the kind of citizen that knowing he could identify the letters together to form words and sentences. Moreover, the dogmatic and traditional education predominated discredit the value of freedom of the subject - readers, since there was a check on the exercise of interpretation, the reading being a mere appropriation an information, ideas and truths found in texts [2].

In Pedagogy of Autonomy may be found a sequence of requirements that according to the author will possibly the achievement of this proposal and the autonomous act of teaching, which is likely to be an important way to real appreciation as the act of reading on itself, as understanding turns into the prior knowledge. Among them we have to teach differently: respecting and instigating the autonomy while being educated; apprehension of reality; curiosity; listening skills; readiness for dialogue; freedom and authority, among others.

Then thinking of a freedom proposal, we realize how to consider each person living history, also realizing how this education immersed in thoughts of policies and guidelines favors certain desires (in this case, of the oppressors). To get into an education that releases it is necessary to reflect, build together and humbly realize that each person is free as an agent of your own knowledge, especially in Brazil where we realize what Paulo Freire affirms: "Brazil was "invented" top-down, authoritarian. It is necessary to be reinvented in other terms." [4].

As a teacher I spare no opportunity to witness the students the confidence with which behave when discussing a topic, to analyze a fact, to state my position in the face of a government decision. My safety does not rest on the false assumption that all know, that I am the "greatest". My safety is founded on the conviction that know something and I ignore something that joins the certainty that I know better what I already know and know what we do not know. My safety is founded on knowledge confirmed by the very existence of that if my inconclusiveness, of which I am aware, attests in one hand, my ignorance; I opened the other, the way to know [6].

Educate to liberate and be free to educate for this, is the proposal of the educator Paulo Freire, while reflecting on the importance of palavramundo promoted the act of reading and its relationship to the construction of interculturality, what demonstrates clearly how the whole theory and practice developed by the Brazilian educator here mentioned in a way to build an education that liberates, that builds knowledge truly valued and useful, as these will be reflected, worked and related to the history of each student.

However, Freire argues that in despite of thinking this relation between power and the education act, this does not mean that education is merely a "reproducer of dominant ideology" [4]. This means that the actual differences between their lives reality, those who live the educational context will be the next to teach, which demonstrates no neutrality on formal or informal educational processes. There is an unfriendly game: while education is a status quo maintainer mechanism and it is done by people with many alive thoughts, giving vibrancy and dynamism to the educational act. Therefore, the analysis of the Adults Education process cannot fails on giving tone to attempts that may promotes a subversion of the oppressive order. What is worse than it is their systematic dropout of school because its whole intellectual work is meaningless to them, since it denies the legitimacy of their thinking, their palavramundo. While it is denied, their practice in and on our complex world are pulled out, and finally the reality is presented as shallow, meaningless to the person itself and the 
school loses its purpose.

\section{Conclusion}

Naturally, it is worth noting that the educator must also see themselves as part of that system, which means that teachers have the responsibility to promote among educators and students, through the knowledge, a relation full of dynamism, changing our reality, studied before as static and lifeless.

Accordingly, the school must consider the student's version of the world making their relationship with the institution less intermittent and more meaningful. The school should consider their palavramundo as a source of knowledge and encouragement to inspire new knowledge that generates more questions and interests.

From this perspective, the Adult School starts to be a space for reflection. Although Youth and Adults Education still seems to be loaded with an banking pedagogy, which intends to compensate students who were excluded from school at the time allotted by law. In agreement with Professor Paulo Freire, it lights on ways to thousands of possibilities, on a path to graduate autonomous citizens and creators of their own lives, contextualizing our reality, our world, with their individual experience, as a participant human being on a social group, on our society.

\section{References}

[1] Arelaro, Lisete. Garcia, Regina Leite. "Que saudades de Paulo Freire!”. In: Revista Trimestral de Debate da FASE, São Paulo, n¹13, Abril/2014.

[2] Carlos, Elter Manoel. "Palavramundo: A leitura como experiência de formação." Dissertação de mestrado do acervo da Faculdade de Letras do Porto. Porto, 2008/2009.

[3] Canclini, Néstor Garcia. Culturas Híbridas. São Paulo: Edusp, 2013.

[4] Freire, Paulo. A importância do ato de ler, os três artigos que se completam. Cortez. Edição 51, volume 22. São Paulo. 2011.

[5] Freire, Paulo. Educação como prática da liberdade. Rio de Janeiro: Paz e Terra, 1967.

[6] Freire, Paulo. Pedagogia da autonomia. EGA. Brasil. 1996

[7] Freire, Paulo. Pedagogia do oprimido. 17ed. Editora Paz e terra, 1987.
[8] MAYO, Peter. "Educação crítica e desenvolvimento de uma cidadania multi-étnica. Uma perspectiva da Europa do sul." Revista Lusófona de Educação, vol. 6. 2005, p. 47-54.

[9] Oliveira, Inês Barbosa de. "Pensando o Currículo na Educação de Jovens e Adultos.” In: Educação de Jovens e Adultos. Oliveira, Inês Barbosa de; Paiva, Jane (orgs.). Rio de Janeiro: DP\&A, 2004. 